\title{
Study of Anticoagulant Dabigatran by Analytical Instrumentation
}

\author{
Bharat Patel, Pravin Ram, Taslimahemad Khatri, Vijay Ram*, Pragnesh Dave \\ Department of Chemistry, KSKV Kachchh University, Mundra Road, Bhuj - 370 001, India \\ *E-mail address: ram_vijay1982@yahoo.co.in
}

\begin{abstract}
Dabigatran with IUPAC name 3-(\{2-[(4-Carbamimidoyl-phenylamino)-methyl]-1-methyl-1Hbenzoimidazole-5-carbonyl\}-pyridin-2-yl-amino)-propionic acid, which can be used to prevent strokes in those with atrial fibrillation due to causes other than heart valve disease, and at least one additional risk factor for stroke (congestive heart failure, hypertension, age, diabetes, and prior stroke), with molecular formula $\mathrm{C} 34 \mathrm{H} 41 \mathrm{~N} 7 \mathrm{H} 5$ was studied in detail for functional group analysis with FTIR, characteristic absorbance by UV-NIR, thermal behavior by TGA-DTA-DSC, particle size and stability of the molecule with Nano particle size analyzer. The structure was confirmed by LCMS/MS with ESI probe and mass was found in aggregation with the reported standard values. The purity of drug was determined by Prep. HPLC analysis. FTIR analysis showed the characteristic peak of carboxylic acid, UV-NIR analysis showed that the $\lambda \max$ was $224 \mathrm{~nm}$ with methanol as a diluent, the compound was found stable in the thermal analysis, the average particle size was found to be 25.2 $\mathrm{nm}, \mathrm{Z}$-average as $0.2 \mathrm{~nm}$ and zeta potential as $-67.6 \mathrm{mv}$ hence showed excellent stability in the zeta potential analysis as per ASTM standards D4187-82, American Society of Testing and Materials, 1985.
\end{abstract}

Keywords: Dabigatran; UPLC/MS/MS; zeta potential; FTIR; UV-NIR; Thermal analysis

\section{INTRODUCTION}

Dabigatran (Pradaxa in Australia, Europe, USA and Canada (previously was Pradax in Canada, name changed to Pradaxa as of January 2013), Prazaxa in Japan) is an oral anticoagulant drug that acts as a direct thrombin (factor IIa) inhibitor. It was developed by the pharmaceutical company Boehringer Ingelheim. Dabigatran can be used for the prevention of stroke in patients with atrial fibrillation [1].

The drug was developed as an alternative to warfarin, since it does not require maintenance of international normalized ratio or monitoring by frequent blood tests, while offering similar efficacy in preventing ischemic events. Unlike warfarin [2].

In early 2013, there is no way to reverse the anticoagulant effect of dabigatran in the event of clinically significant bleeding, and there is still no routine coagulation test suitable for monitoring these patients; specific tests are only available in specialised laboratories [3]. Dabigatran can be used to prevent strokes in those with atrial fibrillation due to causes other than heart valve disease, and at least one additional risk factor for stroke (congestive heart failure, hypertension, age, diabetes, and prior stroke) [4]. 
In practice, warfarin remains the standard drug for patients with atrial fibrillation and a moderate or high risk of thrombosis.

Aspirin is an alternative for low-moderate-risk patients [5]. When the risk is significant and the INR cannot be maintained within the target range despite close monitoring, dabigatran is the alternative to warfarin, provided the patient is closely monitored, especially for changes in renal function [6], adverse events (bleeding) and discontinuation [7].

Dabigatran can also be used to prevent the formation of blood clots in the veins (deep venous thrombosis) in adults who have had an operation to replace a hip or knee [8]. Recently tremendous work has been done in the synthesis of new drugs [9] and various drugs are suspected to come in the market.

For such drugs analysis have been reported by various analytical instruments [10]. Such drugs are needed to be analyzed thoroughly with the highly sophisticated analytical instruments [11].<smiles>Cn1c(CNc2ccc(C(=N)N)cc2)nc2ccc(C(=O)N(CCC(=O)O)c3ccccn3)cc21</smiles>

Figure 1. 3-(\{2-[(4-Carbamimidoyl-phenylamino)-methyl]-1-methyl-1H-benzoimidazole-5carbonyl\}-pyridin-2-yl-amino)-propionic acid.

\section{OBJECTIVE}

Main objective of this study was to become familiar with sophisticated instruments and characterization of the API with different instruments.

\section{MATERIALS AND METHOD}

\section{1. UPLC/MS/MS}

The liquid chromatographic system of Waters Acquity UPLC with PDA (224 nm) and TQD with Mass Link data processing system was used for this entire study and chromatographic separation was achieved by using Waters Acquity BEH C18, 2.4 x $50 \mathrm{~mm}$, $1.7 \mu$ column as stationary phase with binary gradient mode. Sample preparation was carried out by $5 \mathrm{mg}$ Dabigatran drug dissolved in $25 \mathrm{ml}$ of methanol as diluents. Mobile phase ratio was Ammonium Acetate: Acetonitrile (90:10).

\section{2. Nano particle size analyzer with zeta potential}

Analysis was carried out with Nano particle Analyzer 52-100, Horiba and sample preparation was carried out by $5 \mathrm{mg}$ Dabigatran drug dissolved in $25 \mathrm{ml}$ of methanol as diluents. Method for the analysis was scattering angle was $90^{\circ}$, analysis temperature set at 25.0 deg. $\mathrm{C}$ and count rate was $1487 \mathrm{kcps}$. 


\section{3. High performance thin layer chromatography (HPTLC)}

HPTLC analysis was carried out with Desaga AS 30, Desaga Pro-quant system and sample preparation was carried out by $5 \mathrm{mg}$ Dabigatran drug dissolved in $25 \mathrm{ml}$ of methanol as diluents.

Method for the analysis was Start co. X: 50mm, Start co.Y: $48 \mathrm{~mm}$, End co.Y: $52 \mathrm{~mm}$, No.of lanes: 10, Mode: Transmission, Evolution mode: Fluorescence, Slit width: $8.0 \mathrm{~mm}$, Slit height: $1.0 \mathrm{~mm}$, Wavelength: $580 \mathrm{nmand}$ Lamp: Deu/tungsten.

\section{4. Fourier Transform Infrared Spectroscopy (FTIR)}

FTIR analysis was carried out with Shimadzu IRA ffinity-1 CE system with IR Solution software and solid sample was directly analyzed with ATR (Attenuated Total Reflection) system.

Method for the analysis was Measurement mode: \% Transmittance, Apodization: HappGenel, Number of scans: 20, Resolution: 4.0, Range ( $\left.\mathrm{cm}^{-1}\right)$ : Min: 650 and Max: 4000.

\section{5. Thermal analysis (TGA-DTA-DSC)}

Thermal analysis (TGA-DTA-DSC) analysis was carried out with Perkin-Elmer STA8000 system with Pyris software and $11.092 \mathrm{mg}$ of API powder was directly injected into the system.

Method for the analysis was original sample weight: $11.092 \mathrm{mg}$, temperature program: 50 to $400{ }^{\circ} \mathrm{C}$ at $20^{\circ} \mathrm{C} /$ minute and Sample rate set as a standard mode.

\section{6. UV-VIS-NIR spectroscopy: (UV-NIR)}

UV-NIR analysis was carried out with Shimadzu UV-3600 system with UV probe software and sample preparation was carried out by $5 \mathrm{mg}$ Dabigatran drug dissolved in $25 \mathrm{ml}$ of methanol as diluents.

Further $1 \mathrm{ml}$ of this stock solution was taken and diluted up to $50 \mathrm{ml}$ with diluents. Method for the analysis was wavelength for scan mode start at $200 \mathrm{~nm}$ and end at $400 \mathrm{~nm}$, speed for the analysis was set medium.

\section{7. GC-MS analysis}

GC-MS analysis analysis was carried out with Shimadzu make GC-MS QP2010 system with GCMS real time analyzer software in EI mode equipped with a split/split less injector (2500C), at a split ratio of 1/10, using a SGE make BPX5WCOT (Wall coated open tubular) capillary column $(30 \times 0.25 \mathrm{~mm}$ i.d., $0.25 \mathrm{~m}$ film thickness $)$.

The oven temperature was $50{ }^{\circ} \mathrm{C}$ to $300{ }^{\circ} \mathrm{C}$, at $20{ }^{\circ} \mathrm{C} / \mathrm{min}$. Helium was used as a carrier gas at a flow rate of $2.5 \mathrm{ml} / \mathrm{min}$. The injection volume of sample was $1 \mu \mathrm{l}$ and Sample preparation carried out by $5 \mathrm{mg}$ Dabigatran drug dissolve in $25 \mathrm{ml}$ of methanol as diluents. 
4. RESULT AND DISCUSSION

\section{1. UPLC/MS/MS}

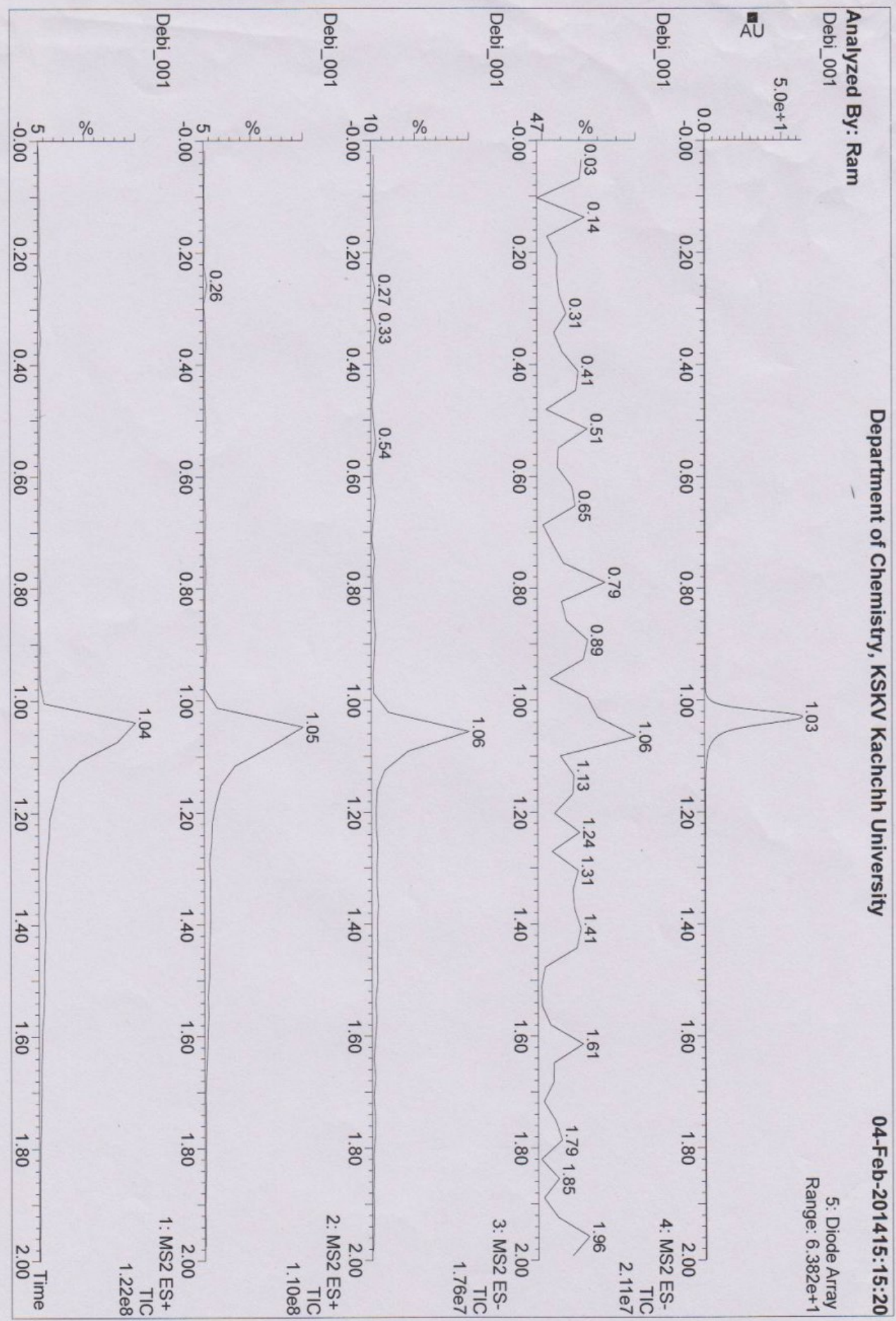


4. 2. Nano particle size analyzer with zeta potential

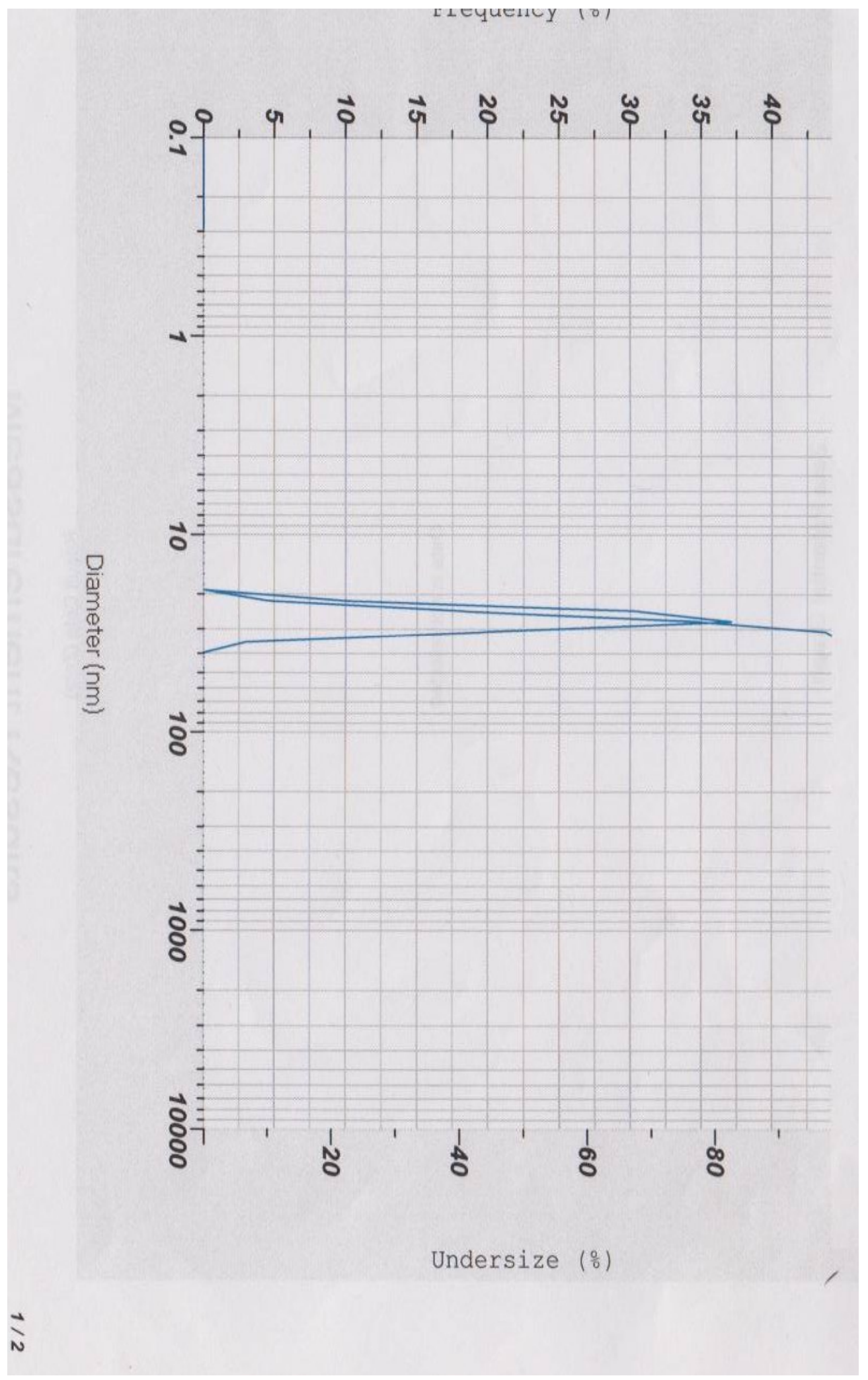


4. 3. Fourier Transform Infrared Spectroscopy (FTIR)

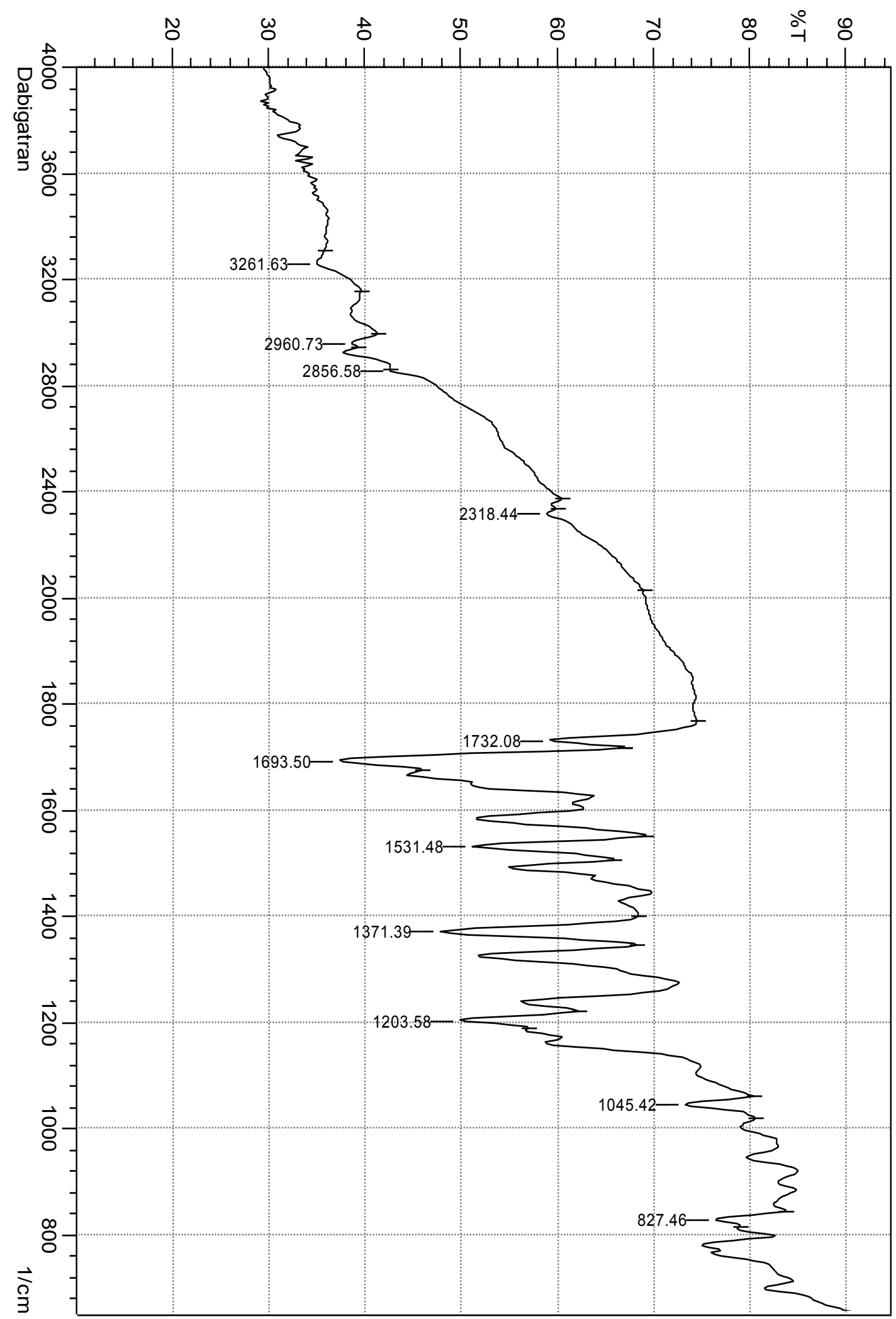


4. 4. Thermal analysis (TGA-DTA-DSC)

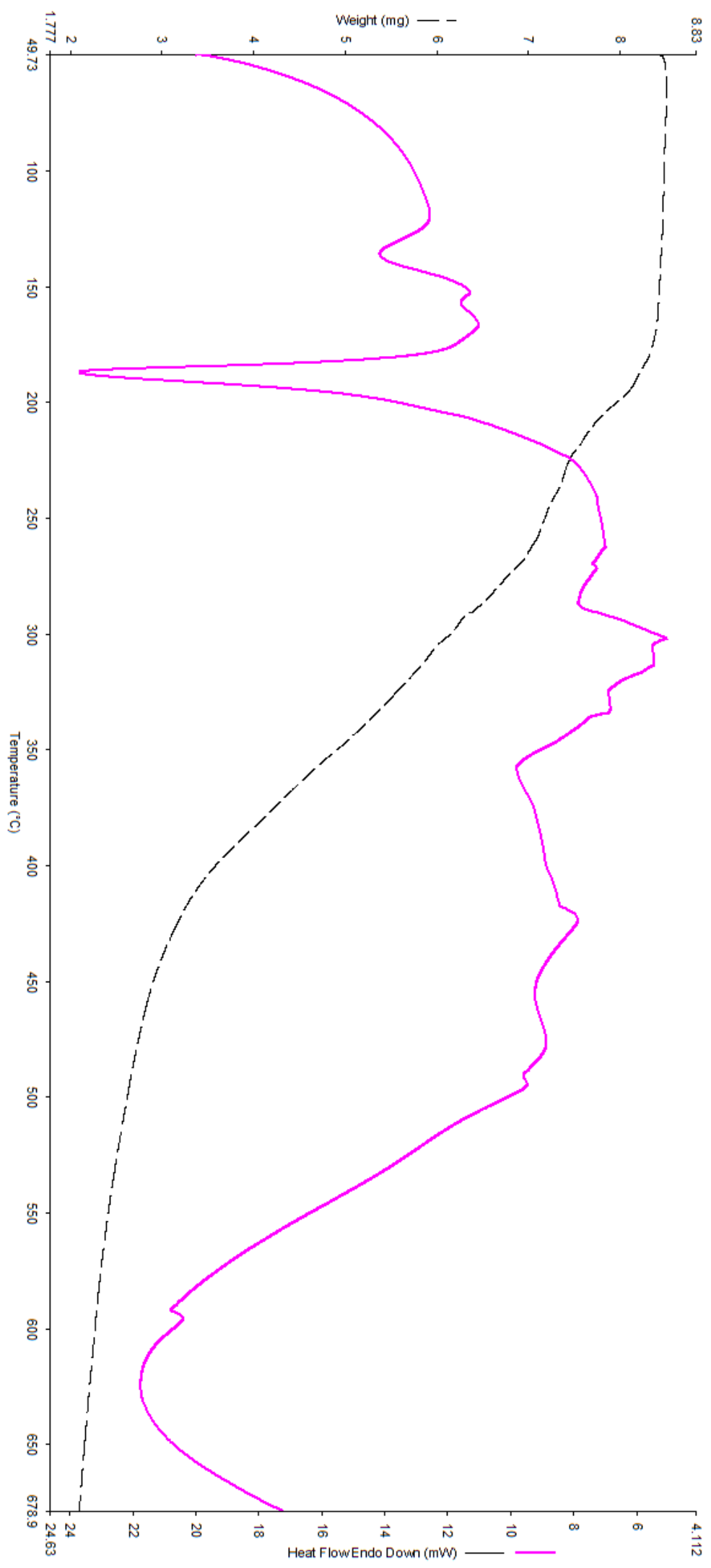


4. 5. Preparative High performance liquid chromatography (Prep. HPTLC)

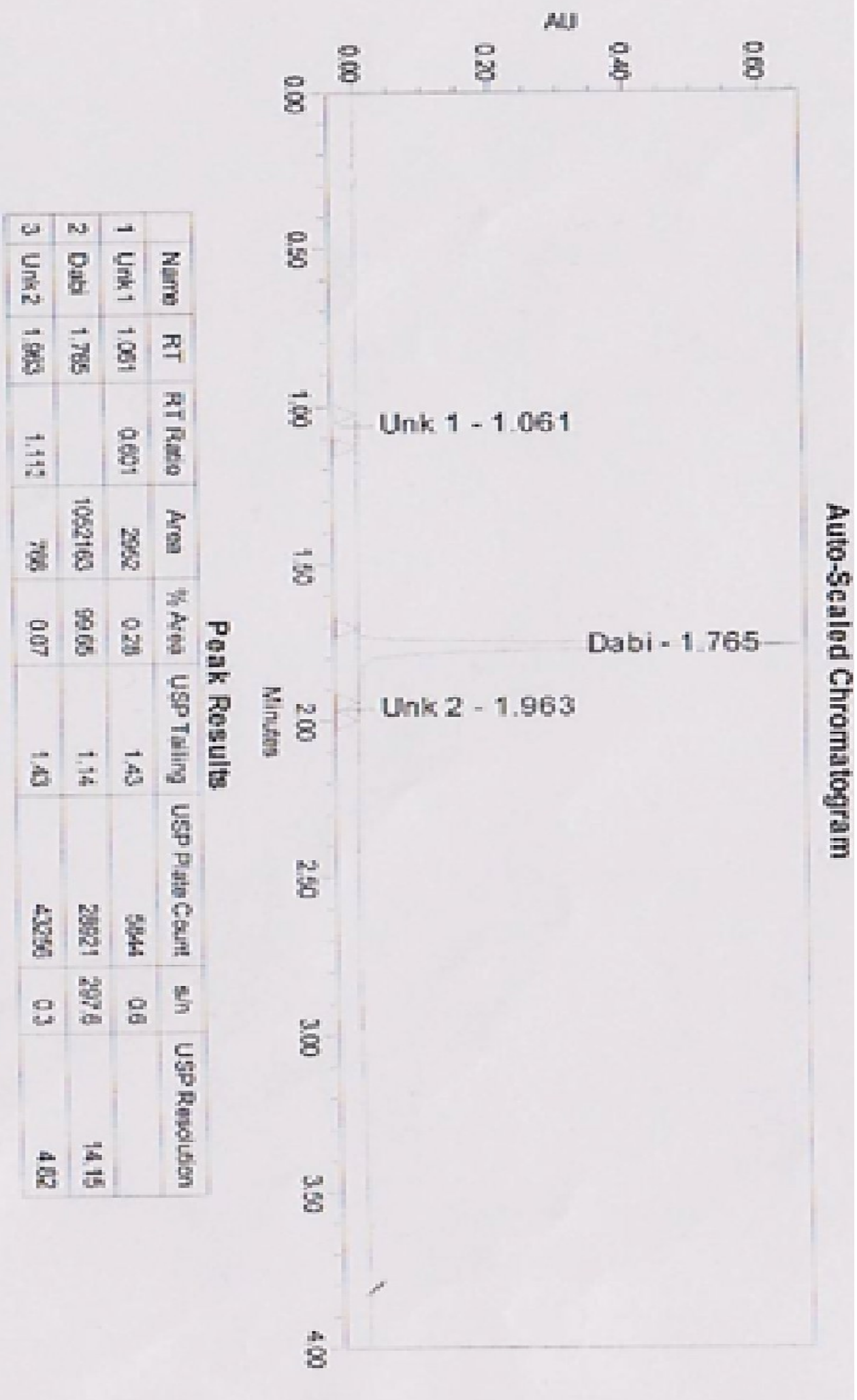




\section{6. UV-VIS-NIR spectroscopy: (UV-NIR)}

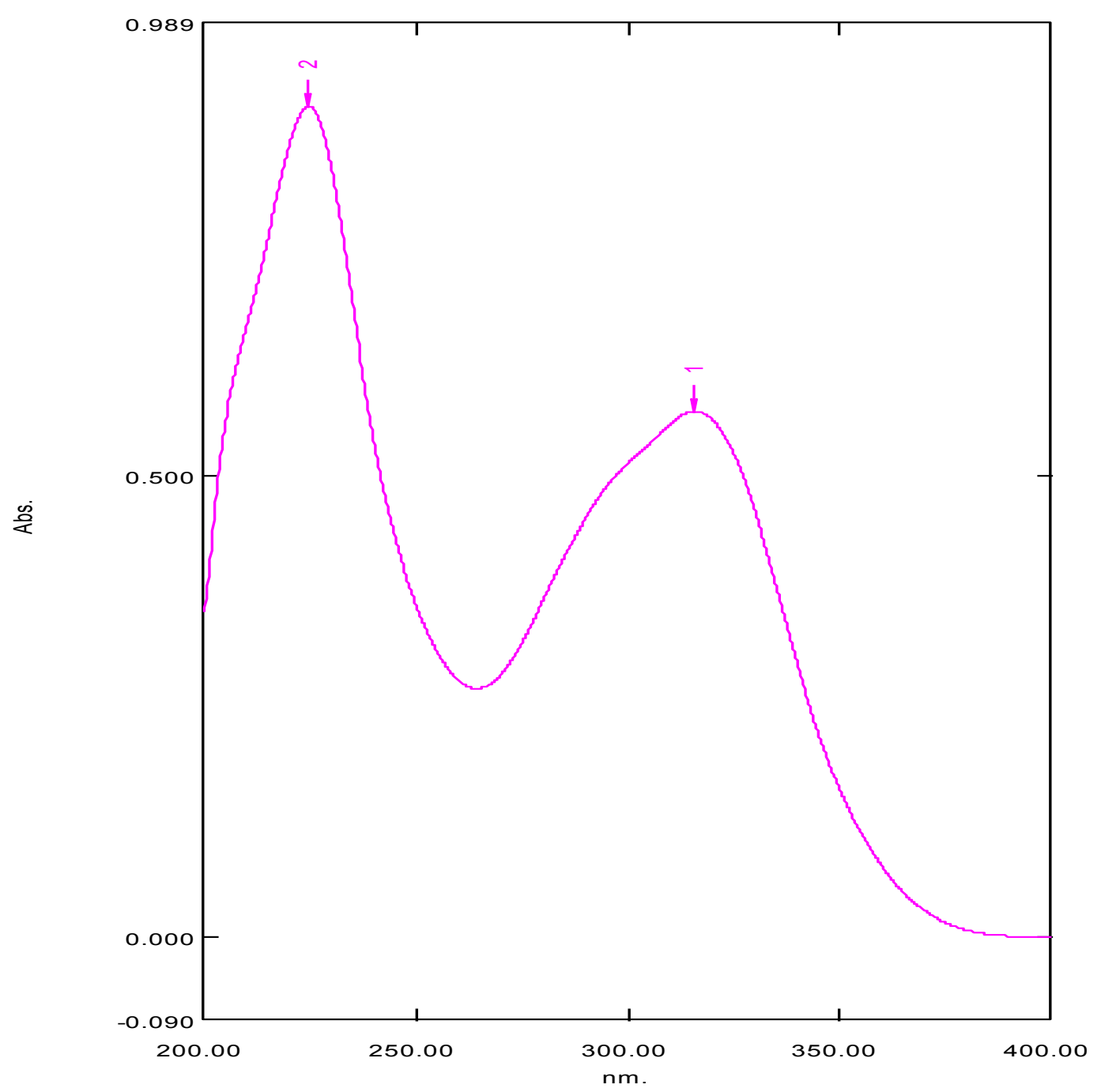

\section{CONCLUSION}

The analyzed drug Dabigatran was found to be highly stable in the thermal analysis, and showed excellent stability in the zeta potential analysis as per ASTM standards D418782, American Society of Testing and Materials, 1985. The average particle size was found to be $25.2 \mathrm{~nm}$, in the range of nano particles. Purity of drug was found $99.65 \%$ in the Preparative HPLC analysis. The FTIR analysis showed all the characteristic functional peaks present in the drug. The LC-MS/MS analysis was carried out in ES+ and ES- modes and gave characteristic mass fragmentation pattern.

\section{ACKNOWLEDGEMENT}

The authors are thankful to Department of Chemistry, KSKV Kachchh University, Bhuj - 370001 (INDIA) for providing facilities. 


\section{References}

[1] Pradaxa Official FDA information, side effects and uses. Drugs.com (2012).

[2] Hanley J. P., J. Clin. Pathol. 57(11) (2004) 1132-1139.

[3] Bleeding with dabigatran, rivaroxaban, apixaban. No antidote, and little clinical experience". Prescrire Int 22(139) (2013) 155-159.

[4] "Pradaxa Official FDA information, side effects and uses". Drugs.com. (2012).

[5] Aguilar M., Hart R., "Antiplatelet therapy for preventing stroke in patients with nonvalvular atrial fibrillation and no previous history of stroke or transient ischemic attacks". Cochrane Database Syst Rev (2005).

[6] "Dabigatran and atrial fibrillation: the alternative to warfarin for selected patients". Prescrire Int 21 (124) (2012) 3336.

[7] Adam SS, McDuffie JR, Ortel TL, Williams JW., Ann. Intern. Med. 157(11) (2012) 796-807.

[8] "Pradaxa". European Medicines Agency (2012).

[9] Khokhani K, Khatri T, Ram V, Patel P., Chemistry \& Biology Interface 3(3) (2013) 192-200.

[10] Ram VR, Dave PN, Joshi HS., Journal of Chromatographic Science 50 (8) (2012) 721-726.

[11] Bhogayta J., Khatri T., Ram V., Dave P., International Letters of Chemistry, Physics and Astronomy 10 (2014) 1-13. 